\title{
Research on the Problem of Legal Supervision of Internet Finance in New Era
}

\author{
Mingwei Xu, Hao Wang \\ Zhejiang University of Finance \& Economics Dongfang College, Jiaxing, 314000, China
}

Keywords: Legal supervision, Internet finance, Online finance

\begin{abstract}
Internet finance is an important driving force to promote the reform of China's financial industry. It has developed many product fields in recent years. Internet finance is a new species produced by the collision of internet industry and finance industry with different culture, making it face many legal risks. This paper discusses the concept, characteristics and risks of internet finance, and gives some suggestions on risk prevention strategies to provide some references for the relevant researchers.
\end{abstract}

\section{Concept of Internet Finance}

With the development of new technologies, such as cloud computing, social network, mobile payment, large data and so on, the internet has opened a new era of human beings. The internet is characterized by its centralization, flatness and self-organization. It creates value through stimulating individual potential and integrates intelligence into intelligence through the internet. Especially in the core of the economy, which is the financial field, it has triggered a new combination and construction of production elements and internet technology, forming a new form of financial business. Through the internet platform, we innovate the form of financial business, embody the financial nature of financing, payment and information intermediary services, and form a new financial form that is different from traditional finance. In the mode of internet finance, payment is very convenient and the asymmetric degree of market information is very low. The cost of capital supply and demand in terms of capital maturity and risk sharing is very low, and direct transaction can be carried out. Banking, securities business and exchanges and other financial intermediaries do not work, the issuance and trading of stocks and bonds, loans, etc. Can be directly on the internet. The market is full and effective, very close to the non-financial intermediation state described by the general equilibrium theorem. Internet finance is not a simple combination of internet and financial industry, but a new mode and new business that is naturally adapted to new needs when users are familiar with the technology at the level of security and mobile internet. It is a new field that combines the traditional financial industry with the internet technology. Internet finance is a new financial service mode that realizes capital circulation by using big data, cloud computing, social networking and search engine and other internet technologies.

\section{Features of Internet Finance in New Era}

\subsection{More Finance Information}

The main body of the market will not exist, will connect with other market players, such as suppliers, users, and so on. It can collect the bank the market information from multiple aspects of information through the Internet, and through a whole understanding of the main body of the market, and the other aspects of the subject information. Through the analysis on the consumption habits of customers in the Taobao search keywords, Ali financial platform can tell customers of possible life level and potential consumer demand. Even by the customer to pay water, electricity and gas charges and another daily consumer address, it can determine whether there is a stable customer accommodation. The platform makes a reasonable judgment on the customer's credit situation. 


\subsection{New Calculation Model}

In the traditional financial model, the information resources are scattered and complex, and the data are difficult to be effectively processed and applied. But the Internet financial model, social network generation and dissemination of information, there is a lot of information of individuals and institutions have no obligation to disclose; and the search engine will organize, sorting and retrieval of information, targeted to meet the needs of information retrieval; cloud computing technology ensures the high processing capacity of massive information. In the cloud computing security under asymmetric information is flat, realizes the data standardization and structured information, and ultimately the formation of time series of continuous and dynamic changes in the financial market, and this information is the traditional financial institutions involved in the subject of urgent need but is unable to get.

\subsection{No Traditional Agency}

The Internet financial model, capital supply and demand information posted on the Internet, the supply and demand sides can easily query transaction object provides transaction records, data analysis through information technology in-depth, comprehensive, in-depth grasp of the transaction object information, and then to find the appropriate risk management tools and dispersion, so that the two sides even multi transaction can the perfect competition. We can maximize the efficiency of capital allocation, and finally achieve the maximization of social welfare. Internet finance is essentially direct financing. The information of capital supply and demand form a full trading possibility set on the internet. After matching the supply and demand of funds, they can directly trade, and effectively solve the financing problem without the participation of financial intermediaries. This mode of disintermediation has eroded the original financial layout and divided the market share of the original financial institutions, which is becoming the focus of the market dispute.

\section{Risks of Internet Finance in New Era}

In the financial development of the internet at the same time, due to lack of legislation in this area of internet banking and internet financial law enforcement is not strict, lack of internet financial regulation, the enterprise and the market competition will occupy the market position naturally, between the blind and supervision of internet financial enterprises can easily walk in the legal loopholes, illegal business behavior and even illegal absorb public deposits, illegal fund-raising phenomenon, accumulated a lot of risk. In the process of internet users through the internet to provide financial services, will face the risk of the lack of law and conflict of laws, vulnerable to legal disputes among the blind, not only increased the hidden costs of transaction cost and transaction process, but also affect the healthy development of internet banking. The rise of internet finance has not been a long time, but the development is very rapid, and the relevant state organs must beware of the bubble of internet finance. New lending institutions and enterprises are emerging every year in the p2p lending platform. The size of these companies is also rising. But every year the bankrupt lending institutions are endless. We should beware of the loss of credit caused by the illegal operation of internet finance, and strengthen the construction and improvement of the credit collection system. The disclosure of personal information is not guaranteed. In general, financial websites require customers to provide personal identity information and other personal privacy information. Once these information is leaked, personal privacy right will not be effectively protected. In recent years, there are frequent incidents of personal information leakage on the internet. These leaks will make honesty and credit disappear, not only impacting business ethics, but sometimes even endangering national security. The protection of personal information is one of the important bases for the development of internet finance. Not only that, the network technology also has security risks. The simple and convenient internet financial industry often ignores the security problems of network technology, related institutions. Enterprises lack specific and effective monitoring and management methods and awareness, which will lead to huge security risks. 


\section{Legal Supervision Strategies of Internet Finance in New Era}

\subsection{Accelerate Legislative Process of Internet Finance}

The combination of huge volume of capital transactions and low security and poor controllability of internet brings high risk to internet finance behind its high development. Therefore, it is imperative to build a perfect legal and regulatory system related to internet financial supervision and strengthen the protection of the rights and interests of the internet financial consumers. At present, laws and regulations to adjust and regulate the internet banking is still in the blank state, and to realize the healthy development of internet banking, it will be necessary in this respect from the fundamental legal norms. Revising and perfecting the existing financial laws and regulations. The development of internet consumption and investment and credit in china, the business transactions in various commercial banks and financial institutions are mainly operated through the internet. This kind of network transaction has the advantages of fast, low cost and so on. It is becoming more and more popular with the public. This electronic transfer of remittances, payments and credit involves the interests of many parties, and the division of responsibility among the economic participants is difficult to determine. This is mainly due to the lack of explicit provisions of the law. We should improve the internet financial legislation and legislate for standardizing the legal responsibility distribution and dispute settlement procedures of internet financial market access, technology standard, security precaution and risk taking. It can not only make the participants of the internet finance more authoritative, but also make the financial legal consequences bear evidence to follow. It is the most important task for the administrative departments to regulate the network finance now by issuing corresponding laws and regulations, determining the legal responsibilities of economic participants, correctly guiding legal behaviors, and standardizing the order of network financial market. For example, the commercial bank law is amended to increase the operation, management and security of the internet, and make it fit with the era of internet finance. Similarly, the amendment of the securities law, the insurance law and the bank supervision and management law must also be needed. Through the definition of internet finance, we should clarify the main body. Before the internet financial legislation has not yet been completed, can be led by the state council, relevant departments and organizations, enterprises, legal experts, open hearings demonstration, widely listen to the views of the community, collate, comprehensive, several opinions about making temporary the healthy development of internet banking.

\subsection{Establish Supervision System of Internet Finance}

The establishment of specialized professional Internet financial supervision departments in the internal system can make the supervision of all fields and industries more powerful, responsible for and supervision. The traditional financial supervision and factors not related to the Internet, the means of supervision and management are generally simple on-site supervision; and Internet banking, the Internet based, so the regulation needs to be rapid, timely and effective supervision, and network off-site supervision building has become a must choose. We should combine with the existing Internet financial risk, with the emergence of new situation, through careful analysis of all kinds of financial enterprises, institutions, specific responsibilities clear regulatory agencies and personnel, to ensure financial laws and regulations can be carried out and put in place, to create a scientific and orderly Internet financial supervision system. Internet banking is a joint financial and financial supervision of the Internet itself has many loopholes and shortcomings, and the regulation of the Internet there exists a certain degree of difficulty. The traditional off-site supervision of financial transactions in the operating procedures and methods, there are many deficiencies. The regulatory agencies and the Department's responsibility is not clear, there is responsibility and authority management. Many participants in the financial process of financial trade, with poor regulation, not to work, disrupt the financial market order, which is of great reference to the network of financial supervision. To establish a network of specialized financial supervision system, using the advanced network information technology, improve the network financial business approval procedures and 
the supervision mechanism, the research and development of hardware and software program for the financial development of the Internet network technology, provide financial support and guidance. We ensure that regulators can meet the environmental requirements of the development of network finance, promote the development of network finance. The revision and perfection of existing financial legal system.

\subsection{Protect Consumer Right of Internet Finance}

In the case of information asymmetry, consumers are in a weak position, and their rights and interests are easily infringed by the Internet financial institutions. Therefore, it is necessary to formulate relevant rights and interest's protection methods, requiring Internet institutions to enhance information transparency, especially in the field of risk allocation and responsibility undertaking, as well as consumer personal information protection and other fields. Facing the new field of Internet finance, there will be new phenomena and challenges in the protection of financial consumers' rights and interests. Therefore, we should attach great importance to and solve these problems in a timely manner, to better protect the rights and interests of financial consumers. For these purposes, one is to establish the protection system of personal information of Internet finance. To clarify the methods and steps of information disclosure, strengthen the protection of personal information, avoid information disclosure, to protect the legitimate rights and interests of consumers. The two is to establish an internet financial personal information base and set up a consulting center. Make the Internet financial participants get correct and appropriate information, and provide relevant advisory services in time to reduce the risk and cost of the transaction. The three is to establish a complaint accepting institution, unimpeded channel of complaint acceptance, and perfect the complaint acceptance mechanism. We can establish a nationwide complaints platform, published telephone complaints, specializes in the development of national financial consumer protection website, accepting the matters relating to the establishment of specialized agencies and personnel responsible for complaints. The four is to set up an early warning platform for Internet financial investment risk, which is to gather information and data from professionals, create a unified and comprehensive data platform, and provide targeted risk warning for high-risk products and businesses. The five is to establish the propaganda and education departments, institutions or associations corresponding to the Internet finance. In addition, the situation of Internet financial mixed operation has appeared. Therefore, we should improve cross industry, cross market and cross regional coordination to protect internet financial consumers. In the aspects of safeguarding rights, Internet financial consumer protection institutions can be established and compensation mechanism and litigation mechanism can be set up. We should use social network to enhance the diffusion of financial consumer education and warning information, to improve the risk awareness and self-protection ability of Internet financial consumers. Aiming at these special groups of Internet financial consumers, we should fully publicize Internet financial knowledge, conduct systematic, scientific and effective education, and effectively improve consumers' awareness of protection and risk tolerance.

\section{Conclusion}

Internet has changed people's communication model, changed the business model, and further changed the traditional financial model. However, internet finance is also not a pure land. If we pursue the model of financial governance based on self-regulation, iternet finance can really benefit millions of people.

\section{References}

[1] Yang Dong. The Legal Regulation of Internet Finance-A Perspective Based on Information Tools [J]. Social Sciences in China, 2015(4): 107-126+206.

[2] Fang Yeyuan. Path of Legal Regulation of Internet Finance [J]. Taxation and Economy, 2016(6): 20-24. 
[3] Tao Zhen. Legal Regulatory Issues in the Internet Financial [J]. Journal of CUPL, 2014(6): 74-78+158.

[4] Huang Tao. Internet finance in China: market, supervision and law [J]. Journal Of Southeast University (Philosophy and Social Science), 2017, 19(4): 84-91+147. 